\title{
The Analysis of the Path Selection of Reducing the Excessive Packaging of Goods from the Perspective of Circular Economy
}

\author{
Zhijuan CHEN \\ Department of Fine Arts, Kaifeng Vocational College of Culture \& Art, Kaifeng City, China \\ Zhijuanchen1688@aliyun.com
}

\begin{abstract}
Keywords: commodity, excessive packaging, circular economy
Abstract. At present, the market is filled with the excessive packing of the goods, which not only misleads consumers and damage the interests of the consumers. More importantly, this phenomenon results in the waste of resources and energy and the pollution of environment, which disobeys the development of circular economy and the building of the economical society in China. The author believes that China should pass legislation to strictly define and limit the excessive packing of the goods, consumers should change the consumption idea to make excessive packaging without living space, and the manufacturer should change management concept to adapt to the mainstream trend of the global low carbon economy and the development of green packaging.
\end{abstract}

\section{Introduction}

Packaging is the general term of the containers, materials and assistants according to certain technical methods in the process of circulation for products protection, convenient transportation and sales promotion. From the definition of packaging, the basic function of packaging are products protection, convenient transportation and sales promotion. Packaging before consuming plays a protective role for the environment, extends the expiration date of consumer goods and reduce the waste of resources and environment pollution due to the consumer goods deterioration. So the packaging now has a benign impact on environment and is beneficial for the optimization and development of the environment; However the packaging after consumption has a bad effect on the environment. With the development of economy, the aggravation of the international economic competition and the transformation of the consumption idea, our country market is full of excessive packaging goods. The excessive packing of the goods is not only causes the waste of resources and energy and the misleading of consumers, but more importantly the packaging waste poses a grave threat to the environment. This kind of phenomenon is against to the overall goal currently advocated in our country, that is the development of the low carbon cycle economy and the construction of the economical society.

\section{The definition of excessive packaging of goods}

Excessive packaging refers to the packaging that is far more than its function, and the packaging used is beyond the items range of the protection of packaging, which reflects that the packaging is too big and too much, and its outstanding characteristic is packing in excess. The excessive packaging has various forms, and analyzed respectively from the packing quantity, degree, and shape. etc. The excessive packing of the "quantity", refers to the quality and quantity of packaging go beyond the scope of protection of packaging items; In terms of quantity, it shows that the packing layer and the number of packing is too much, which increases the quantity of piece, thickness and the number of unnecessary packaging; In terms of quality, it shows that the excessive packaging quality, the excessive unit of packaging and the imbalanced ratio between packaging and goods. The excessive packing of the "degree", mainly reflected in the excessive packaging of thickness, length and width of packaging, by increasing the thickness of the packaging materials, embedding the fillings in the structure of the packing space, increasing the amount of packaging material, and even designer leads to the excessive packaging width for visual effect. The excessive packing of the "shape", embodied in 
the large space of packaging and packaging goods, usually far greater than the product form. In addition, the excessive packing of the color refers to that it can use black and white packaging, but with the color packing, and it can use single color packing but with double color packing or multicolor.

\section{The harm of excessive packaging of goods}

There are several facts showing the disadvantage of excessive packing:

Do harm to the environment

Packaging pollution to the environment is embodied in three aspects, that is, packaging production process, packaging materials or packaging containers and packaging waste, caused by the pollution. Specifically, part of the packaging industry production of raw materials processed into packaging products, part of the raw materials discharge directly into the environment, such as some packing industries emission from all kinds of waste gas, waste water, waste residue and cannot be recycled packaging materials in the process of production pollution to the environment. Because of their chemical composition some of the packing materials change the content or pollution of the environment, packaging are disposable, nearly $80 \%$ of packaging products become packaging waste, so the packaging waste pollution to the environment is obvious. The excessive packaging and the pollution is becoming more serious. The excessive packaging materials, manufacturing to become waste is totally damaged to the environment. According to the sanitation department statistics, in the nearly 3 million tons of garbage, all kinds of commodity packaging accounts for roughly 830,000 tons, and almost 600,000 tons can reduce excessive packaging. Thus, the harmful for the environment can not be ignored any more.

Waste of resources and energy

At present, the commodity packing material from natural plants and ceramics changed to paper, plastic, glass, metal, the pattern of the four categories of materials. As the diversification of packaging materials, the world consumption of packaging materials also grows per capita. According to incomplete statistics, at present the world per capita consumption of packaging materials are 145 $\mathrm{kg} / \mathrm{year}$, the United States leads the world in per capita packaging material consumption of up to 250 $\mathrm{kg}$ per year, $200 \mathrm{~kg} /$ year in Japan, China is only $30 \mathrm{~kg} / \mathrm{year}$. But as large population base, the packaging material consumption in China absolute number is more than 30,000,000 tons. Statistics show that at present the packing boxes in China are reached 240,000 tons every year, equivalent to cut down 1.68 million thick trees. Although in China some of the waste can be comprehensively used such as some solid waste and recycled of renewable, other packing can not be recycled, it values more than 50,000 million yuan. Now days there are patches of forest becomes into wrapping paper, excessive packaging compounded on the verge of exhaustion of resources, lack of more.

The burden of consumer

The excessive packaging increases the cost of commodity. In most cases, the cost realized by increasing the price of goods to the consumers. In this situation, without increase the prices of commodity, the merchant will compensate for the cost of excessive packaging by reducing the quality or quantity of the packaging product, eventually led to the burden on consumers and do harm to the interests of consumers.

\section{Foreign restrictions on excessive packaging}

Over packaging could bring environmental pollution, waste of resources and energy and the detriment of consumers. Therefore, many of the developed countries make the corresponding definition and punishment on over packaging. Germany and Japan are the most economic countries on energy-saving packaging all over the world. They are also the first two nations to study how to limit over packaging. As early as 1975,the Federal Food Packaging Institute in Munich, Germany held a seminar on the "most appropriate packaging", which showed the state's attitude on this issue. The state would focus on reducing packaging material and packaging costs, and seeking to achieve the most appropriate standardized container size, capacity. Germany had begun to advocate "unpackaged" and 
"simple packaging" for commodities a decade ago, stressed the packaging should be friendly environment and do no harm to human health and easy to recycling, which help to save energy and resources. If certain goods manufacturers choose to package, they must pay for the "waste recycling fee."

In addition to paying the cost of packaging materials, manufacturers should also pay for future recycling costs, in that way manufacturers had to emphasize on packaging design which could help reduce production costs. To prevent deceptive packaging, Japan enacted the "Packaging the new guidelines", its provisions include: to minimize the volume of packaging containers, empty containers should not exceed $20 \%$ of the vessel volume, packaging costs shall not exceed $15 \%$ of the price of products, and packaging should display the correct value of the product, in order to avoid misleading consumers.

South Korean government believes that excessive packaging is an act of guilty, if the manufacturer does not reduce product packaging ratio and the number of layers in accordance with government regulations, it will be fined up to three million won. In order to implement restrictions on pharmaceutical packaging ratio and number of layers, the Korean government has put forward three major measures to regulate manufacturers. That is to check the package, to reward labeling and to punish for violation of packaging standards.

\section{Suggestion on achieving simplification of packaging}

Circular economy is the key to the ecological economy, and has become the an effective model for the international community to promote the sustainable development. Circular economy is a friendly environment economic development model to achieve the reduction of resources and the re-use of products, which emphases on "clean production". It is "resources - products - renewable resources "feedback cycle process, and ultimately to achieve" optimum production, optimum consumption and minimum waste. "China is vigorously promoting the recycling economy and taking a new way to industrialization.

In the development of packaging industry, the implementation the circular economy and rectification of the current over-packaged commodity not only requires the government's initiative, enterprise self-discipline, but also need the participation of the majority of the public awareness and participation capabilities.

excessive packaging through legislative restrictions

Excessive packaging is popular, which is heavily related to the public's environmental unawareness. And the ineffective regulatory of the state, and their tolerance and connivance would be the key factors to breed these phenomenon. Although on December 1, 1998 the country began to implement food safety "Packaging Standard consumer needs," which defined the national standard. It limits false packaging to fundamentally prevent the deception of consumers.

But we should see that it just give out the provision for excessive packaging in principle, but did not develop professional standards for packaging, excessive packaging and penalties for excessive packaging. This makes no provisions to implement a uniform measure and standard.

During the Mid-Autumn festival in 2000, the problem of moon cake excessive packaging aroused strong concern in society. On the 2005 national "two sessions", Zhe JiangTuan, deputy of the National People's Congress submit suggestion that is aimed at formulating and perfecting the laws and regulations and standards of commodity packaging, to resolve the problems of the goods excessive packing, serious waste of resources and the destroying of environment. Therefore, the National standardization Management Committee fermented a new national standard to make moderate regulation on the moon cake packaging. On July 5, 2005, the National Development and Reform Commission and other four ministries jointly issued notice which stipulates the price, quality, packaging and tied sale. etc. And it also clearly states that tied sale should not appear in the sale of moon cake. Operators should use toxin-free, non-hazardous, easily degraded and easily recycled materials for moon cake packaging to reduce the excessive use of packaging materials. The new 
standard of moon cakes packaging has been issued, which makes specific provision of the cost and packaging of moon cake and other specific details. It stipulates as follows: packaging cost is not higher than $20 \%$ of the retail price. Therefore, "sky high-priced moon cakes", "excessive packaging" and other phenomenon will be curbed.

Manufacturers should establish a correct concept of packaging

The profit motive of the manufacturers and sellers is the primary source of this phenomenon, so the country should be strictly defined and punished the excessive packing by laws and regulations. As a manufacturer, he or she should realize the threat posed by excessive packaging for enterprise survival.

Setting up correct concept of packaging: Under the background of the nation vigorously advocating the development of circular economy and building conservation-minded society, the country's forthcoming restrictive provisions about the excessive packing and the transformation of the consumption idea are clearly very adverse to merchandise manufacturers continuing to excessive packaging. And with the global shortage of natural resources, especially the lack of the ownership of natural resources per capita, the excessive packing of the goods will greatly increase the cost and be bad for improving enterprise competitiveness. Therefore, only the enterprises establish the people-oriented concept of packaging and show a correct attitude towards the promotion function of the commodity packaging, could they walk out from the pitfalls of excessive packaging.

Follow the principle of the development of circular economy: Circular economy is a systemic industrial change and the fundamental change from the domination of market demand of product profit maximization to following the sustaining construction of ecological sustainable development ability. Principles of circular economy can be summarized as "3R" principle, namely "Reduce, Reuse and Recycle". Specific to the packaging industry, one is to reduce the amount of raw materials of packaging, namely "reduction" principle, and manufacturers save resources and reduce emissions by reducing raw materials and optimize the manufacturing process; The other one is to improve the recycled material content in the packaging products, namely "recycle and reuse" principle.

To guide consumers to environmentally and friendly packaging consumption

There is a great relationship between excessive packaging and consumer's error attitudes toward packaging. Therefore, it is necessary to carry on the beneficial environmental protection guidance to the consumer's concept of packaging consumption. Environmental protection guide on packaging consumption, mainly refers to the consumer in the purchase, use, and disposal of many aspects of the guidance, in the purchase of goods, the use of packaging, to promote green consumption. State environmental protection departments, non-governmental environmental organizations, educational institutions and the media should increase the publicity and education of the knowledge of green packaging, the relevant departments should instill some basic principles of consumption about environmental protection and green consumption. The first is the appropriate principle, in the packaging, if it can be simplified or use a small package, it will not use a large package, if it can use simple packaging, it will not use gift packaging. For example, in Germany, regardless of wine or whiskey is a simple bottle, thus eliminating the need for packing box. The second is to let consumers accept new technologies, concepts of new rules. The relevant departments expressly prohibited some packaging containers, packaging materials, such as EPS fast food boxes, EPS instant noodles box. As consumers, we should consciously refuse to consume these prohibited packaging containers. For some obviously excessive packaging of goods, consumers should refuse to consume goods having excessive packaging from the perspective of environmental protection and rational consumption, and through preferential purchase of packaging simple, recycling products to reduce the generation of packaging waste, from the consumer's aspect to eliminate excessive packaging.

\section{References}

[1] Wei Junyan. The Damage of Excessive Packaging to the Environment and the Countermeasures, Science and Technology Information,2012(29), p 429-430. 
[2] Zhang Naiming. On the Legal Regulation of Excessive Packaging of Goods, Journal of Shanghai Business School,2012(2), p 10-13.

[3] Li Zhengdong. Current Situation Investigation of Food Excessive Packaging and Improvement Measures, China Packaging Industry, 2015(Z2), p 90-92.

[4] Yang Fuxin, Hou Linqing. The Recycling of Packaging Materials and the Urban Environment. Chemical Industry Press. 2002

[5] Wu Jun, Li Heping. Green Packaging. China Light Industry Press. 2000. 